\title{
First experience with a paracorporeal artificial lung in a small child with pulmonary hypertension
}

\author{
Avihu Z. Gazit, MD, ${ }^{\mathrm{a}}$ Stuart C. Sweet, MD, ${ }^{\mathrm{b}}$ R. Mark Grady, MD, ${ }^{\mathrm{c}}$ and Charles B. Huddleston, MD, ${ }^{\mathrm{d}}$ \\ St Louis, Mo
}

Stabilizing children with decompensating refractory pulmonary hypertension may require extracorporeal circulatory support. Currently, options in this regard are limited to use of venoarterial extracorporeal membrane oxygenation (ECMO), but this approach is frequently fraught with complications. Alternatively, the interventional pumpless lung-assist membrane ventilator (Novalung $\mathrm{GmbH}$, Heilbronn, Germany) can be used through a femoral artery to femoral vein shunt in patients with end-stage lung disease and hypercapnia or hypoxemia refractory to mechanical ventilation and through a pulmonary artery to left atrium shunt in patients with refractory pulmonary hypertension. The latter configuration has several advantages for children with pulmonary hypertension: (1) It provides a parallel low resistance circuit that drastically decreases right ventricular (RV) afterload and native pulmonary pressure, allowing RV recovery and pulmonary vascular remodeling. (2) It may serve as a long-term pulmonary assist device or as a bridge to lung transplant or a bridge to recovery. (3) It allows physical rehabilitation. Here we report the first successful use of the Novalung surgical lung-assist (sLA) device in a small child with pulmonary hypertension.

\section{CLINICAL SUMMARY}

A 2-year-old boy $\left(13.6 \mathrm{~kg}\right.$, body surface area $\left.0.62 \mathrm{~m}^{2}\right)$ was seen in extremis after a 3-month history of anorexia, intermittent diarrhea, and rash. He was transported to our hospital after tracheal intubation, initiation of mechanical ventilation, and inotropic support. A diagnosis of pulmonary hypertension was made with transthoracic echocardiography, prompting administration of inhaled nitric oxide (Table 1). On day 2, venoarterial (right internal jugular

\footnotetext{
From the Divisions of Critical Care and Cardiology, Department of Pediatrics, ${ }^{\text {a }}$ the Division of Allergy, Immunology, and Pulmonary Medicine, Department of Pediatrics, ${ }^{\mathrm{b}}$ the Division of Cardiology, Department of Pediatrics, ${ }^{\mathrm{c}}$ and the Division of Pediatric Cardiothoracic Surgery, Department of Surgery, ${ }^{\mathrm{d}}$ Saint Louis Children's Hospital, Washington University in Saint Louis, Missouri, St Louis, Mo.

Disclosures: Authors have nothing to disclose with regard to commercial support.

Received for publication Nov 15, 2010; revisions received Jan 6, 2011; accepted for publication Feb 9, 2011; available ahead of print Mach 21, 2011.

Address for reprints: Avihu Z. Gazit, MD, Divisions of Critical Care and Cardiology, Department of Pediatrics, Saint Louis Children's Hospital, Washington University in Saint Louis, One Children's Place, Northwest Tower, 8th floor, St Louis, MO 63110 (E-mail: gazit_a@kids.wustl.edu).

J Thorac Cardiovasc Surg 2011;141:e48-50

$0022-5223 / \$ 36.00$

Copyright (c) 2011 by The American Association for Thoracic Surgery doi:10.1016/j.jtcvs.2011.02.005
}

vein-right carotid artery) ECMO support was initiated because of (1) worsening hypoxemia related to shunting across the atrial septum (oxygen saturation $75 \%-82 \%$, $\mathrm{PaO}_{2} 43-51 \mathrm{~mm} \mathrm{Hg}$, inhaled nitric oxide $40 \mathrm{ppm}$, inspired oxygen fraction 1), (2) severely decreased right ventricular (RV) systolic function consequent to suprasystemic pulmonary pressures (echocardiographic estimate of RV pressure was $88 \mathrm{~mm} \mathrm{Hg}$ with right atrial $\mathrm{V}$ wave, systolic femoral arterial blood pressure was $81 \mathrm{~mm} \mathrm{Hg}$ ), and (3) severe metabolic acidosis ( $\mathrm{pH} 7.23, \mathrm{PaCO}_{2} 38 \mathrm{~mm} \mathrm{Hg}$, base excess -11.2 ), despite escalating inotropes (epinephrine $0.08 \mu \mathrm{g} /$ [kg $\cdot \min ]$, dopamine $15 \mu \mathrm{g} /[\mathrm{kg} \cdot \min ]$, milrinone $0.5 \mu \mathrm{g} /$ $[\mathrm{kg} \cdot \mathrm{min}])$. During the period of ECMO support (17 days), the patient was listed for lung transplant. Because we expected a prolonged ECMO course before transplantation, with an anticipated survival of only $40 \%$ for children with idiopathic pulmonary arterial hypertension supported with ECMO according to our experience and data obtained from the ECMO Registry of the Extracorporeal Life Support Organization (ELSO), ${ }^{1}$ we decided to transition our patient to paracorporeal Novalung sLA support. As stipulated in the Food and Drug Administration's Guidance for Compassionate Use, we reviewed the case with the Washington University School of Medicine human research protection office and discussed the risks and benefits of the Novalung sLA device at length with this patient's parents, who agreed to proceed with this plan.

Novalung sLA device implantation was performed while the patient was attached to ECMO. The sLA device was interposed in a shunt created between the main pulmonary artery and the left atrium. As expected, the low-resistance oxygenator circuit acutely decreased RV afterload and achieved normal gas exchange while bypassing the native, high-impedance, pulmonary vasculature, allowing separation from ECMO immediately after establishment of the sLA shunt. To create the shunt, $12 \times 9-\mathrm{mm}$ arterial Berlin heart cannula (Berlin Heart AG, Berlin, Germany) was sewn to the pulmonary artery in an end-to-side fashion, and a 22F DLP right-angle single-stage venous cannula (DLP Medtronic, Inc, Grand Rapids, Mich) was placed in the left atrium. ATransonic HT110 bypass flowmeter (Transonic Systems, Inc, Ithaca, NY) and a $3 / 8$-inch flow probe were used to monitor Novalung sLA device flow. A Sechrist 3500 low-flow air-oxygen mixer (Sechrist Industries, Inc, Anaheim, Calif) was used to control Novalung gas flow and inspired oxygen fraction. Medical therapy for 
TABLE 1. Pulmonary vasodilator therapy and significant interventions during the child's hospitalization

\begin{tabular}{|c|c|c|c|c|c|}
\hline Date & iNO dose & Sildenafil dose & Bosentan dose & Flolan dose & Significant event \\
\hline June 11, 2010 & $40 \mathrm{ppm}$ & & & & \\
\hline June 12,2010 & $20 \mathrm{ppm}$ & & & & ECMO cannulation \\
\hline June 14, 2010 & $30 \mathrm{ppm}$ & & & & \\
\hline June 15,2010 & $20 \mathrm{ppm}$ & & & & \\
\hline June 29, 2010 & Stop & & & & Novalung* placemen \\
\hline June 30, 2010 & $20 \mathrm{ppm}$ & & & & \\
\hline July 3,2010 & $20 \mathrm{ppm}$ & $4.5 \mathrm{mg}$ QID & & & \\
\hline July 6,2010 & 20 ppm (nasal cannula) & & & & Extubation \\
\hline July 12, 2010 & 20 ppm (nasal cannula) & $6.0 \mathrm{mg}$ QID & & $6 \mathrm{ng} /(\mathrm{kg} \cdot \mathrm{min})$ & \\
\hline July 13,2010 & 20 ppm (nasal cannula) & & & $9 \mathrm{ng} /(\mathrm{kg} \cdot \min )$ & \\
\hline July 22, 2010 & Stop & & & & Novalung* removal \\
\hline July 23, 2010 & & & $31.25 \mathrm{mg} \mathrm{BID}$ & $20 \mathrm{ng} /(\mathrm{kg} \cdot \mathrm{min})$ & \\
\hline July 24, 2010 & & & & $21 \mathrm{ng} /(\mathrm{kg} \cdot \min )$ & \\
\hline Aug 11, 2010 & & $10 \mathrm{mg}$ TID & & $27 \mathrm{ng} /(\mathrm{kg} \cdot \min )$ & \\
\hline Aug 23, 2010 & & & & $29 \mathrm{ng} /(\mathrm{kg} \cdot \mathrm{min})$ & \\
\hline
\end{tabular}

$i N O$, Inhaled nitric oxide; $E C M O$, extracorporeal membrane oxygenation; $Q I D$, 4 times daily; $B I D, 2$ times daily; $T I D$, 3 times daily. *Novalung surgical lung-assist device; Novalung GmbH, Heilbronn, Germany.

pulmonary hypertension was escalated further during Novalung support (Table 1). Device flow remained stable during the course of the first 14 days after its placement $(1.978 \pm$ $0.03-2.28 \pm 0.02 \mathrm{~L} / \mathrm{min}$ ) and then diminished gradually before device removal, reaching a new baseline $\left(1.872 \pm 0.03-1.609 \pm 0.03 \mathrm{~L} / \mathrm{min}\right.$; Figure 1). Initial $\mathrm{PaO}_{2}$ and $\mathrm{PaCO}_{2}$ after device placement were $331 \mathrm{~mm} \mathrm{Hg}$ and $39 \mathrm{~mm} \mathrm{Hg}$, respectively. On day 26, the patient was extubated and allowed to mobilize in bed (Figure 2). Anticoagulation was maintained with heparin infusion (target activated clotting time 160-200 seconds); however, periodic circuit changes were required because of clot formation. On day 42, after 17 days of ECMO and 23 days of Novalung support, our patient had an acute embolic stroke in the left middle cerebral artery distribution. The sLA device was removed later that day. The stroke was acutely manifested by dense hemiparesis and aphasia; both findings were nearly resolved by discharge. Three months after the original presentation, the patient was discharged home treated with continuous infusion of epoprostanol (Flolan; Table 1). An echocardiographic estimate of the RV pressure 6 months after initial presentation was $51 \mathrm{~mm} \mathrm{Hg}$ with right atrial $\mathrm{V}$ wave.

\section{DISCUSSION}

Currently, ECMO provides the only viable support for children with life-threatening cardiopulmonary failure associated with idiopathic pulmonary arterial hypertension. To assess the outcome of children with idiopathic pulmonary arterial hypertension (International Classification of Diseases, 9th Revision, Clinical Modification diagnosis code 416.0) supported with ECMO, we queried the ELSO registry database ${ }^{1}$ for children between the ages of 1 month and 18 years from January 1986 to July 2010. A total of 48 children carrying this diagnosis were placed on ECMO support during that period, with a median duration of support of 7 days (range, 3 hours-39 days). Of those children, 19 survived $(40 \%)$, and multiple complications were reported. ${ }^{1}$ These data are supported by a recent review of our institutional lung transplant database, ${ }^{2}$ which revealed that the need for perioperative ECMO support is associated with significant morbidity and mortality in the pediatric lung transplant population. Our data also notably indicated that the waiting period for suitable donor organ availability is rarely shorter than 39 days, ${ }^{2}$ the longest period of successful ECMO support for pulmonary hypertension reported in the ELSO registry. ${ }^{1}$ A pumpless, low-resistance artificial lung may expose the patient to fewer complications associated with consumption of coagulation factors or hemolysis.

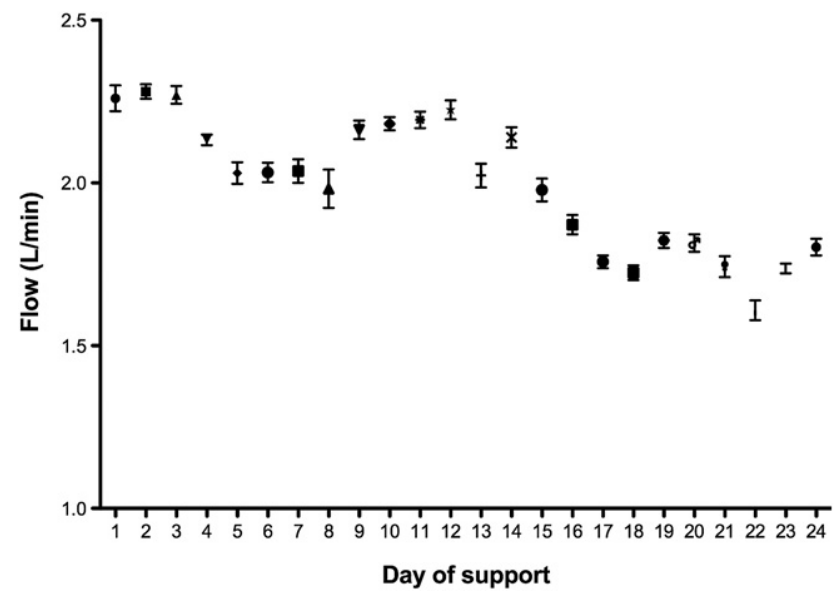

FIGURE 1. Hourly Novalung (Novalung GmbH, Heilbronn, Germany) surgical lung-assist device flow readings presented as mean \pm SEM. Day 1 is the day of Novalung placement and day 24 is the day of the device removal. Note the decrease in baseline flow rates occurring around day 14. 


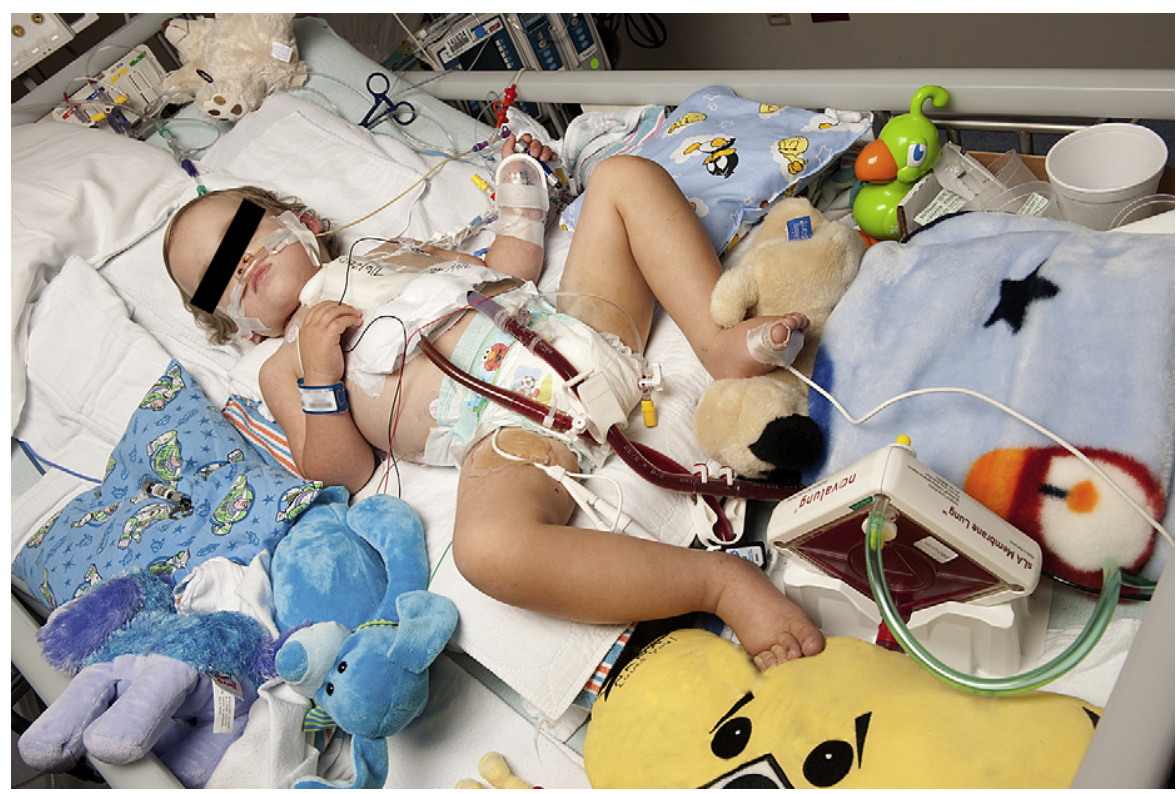

FIGURE 2. The patient is extubated and allowed to mobilize in bed.

The parallel, low-resistance, RV to left atrium shunt significantly reduces RV afterload and vascular wall stress during pulmonary vasodilator therapy. On the basis of studies in animals and in patients with congenital heart disease, as well as our own experience in children with heart failure-related pulmonary hypertension supported with a biventricular assist device (Berlin Heart VAD), we have concluded that pulmonary vasodilator therapy combined with extracorporeal or paracorporeal decompression of the pulmonary vascular bed facilitates reverse remodeling and response to therapy in severely advanced pulmonary hypertension. ${ }^{3,4}$ We speculate that by lessening wall stress such hemodynamic unloading ${ }^{5}$ confers benefit by dampening the pathologic signaling that maintains increased pulmonary vascular tone and hypertrophy. The stroke that our patient had was indeed a major complication; however, this event appears to have been reasonably tolerated, is resolving, and does not preclude our patient's candidacy for lung transplantation. The unique combination of Novalung sLA support and aggressive pulmonary vasodilator therapy permitted an entirely unexpected outcome: discharge home with no immediate need for lung transplant. Our patient's clinical improvement highlights the need for a controlled trial of this device in children with pulmonary failure related to different etiologies in the pediatric population.

We acknowledge the creativity and dedication of all our perfusionists: Michael S. Longo, BS, CCP, Steve C. Raithel, BS, CCP, Mark P. Shepard, BSN, RN, CCP, Arti R. Patel, MS, CCP, and Mark J. Anderson, MS, CCP. Special thanks to Mary Mehegan, RN, BSN, CCRN, Deirdre J. Epstein, RN, BSN, and our cardiac anesthesia team and dedicated CICU nursing staff, Dr Michael Noetzel, chief of Pediatric Neurology, and Dr Allan Doctor, chief of Pediatric Critical Care Medicine.

\section{References}

1. Extracorporeal Life Support Organization. ECMO registry of the Extracorporeal Life Support Organization (ELSO). Ann Arbor (MI): The Organization; September 2010. Available at: http://www.elso.med.umich.edu/Registry.html.

2. Puri V, Epstein D, Raithel SC, Gandhi SK, Sweet SC, Faro A, et al. Extracorporeal membrane oxygenation in pediatric lung transplantation. $J$ Thorac Cardiovasc Surg. 2010;140:427-32.

3. Gandhi SK, Huddleston CB, Balzer DT, Epstein DJ, Boschert TA, Canter CE. Biventricular assist devices as a bridge to heart transplantation in small children. Circulation. 2008;118(14 Suppl):S89-93.

4. Gandhi SK, Grady RM, Huddleston CB, Balzer DT, Canter CE. Beyond Berlin: heart transplantation in the "untransplantable." $J$ Thorac Cardiovasc Surg. 2008;136:529-31.

5. Rich S. The current treatment of pulmonary hypertension: time to redefine success. Chest. 2006;130:1198-202. 